\title{
Prevalence, Patient Predictors, and Referral Patterns for Diabetes-Related Complications Treated at a Central Hospital in KwaZulu Natal
}

\section{Sifiso Mtshali (iD \\ Ozayr Mahomed (D)}

Discipline of Public Health Medicine, University of KwaZulu Natal, Durban, South Africa
Correspondence: Sifiso Mtshali Discipline of Public Health Medicine, University of KwaZulu Natal, 227 George Campbell Building, Howard College Campus, Durban 400I, South Africa Tel +27-3I 260-4382

Fax+2731 2604III

Emailsmtshali@wol.co.za
Purpose: Poor diabetes control can result in short- and long-term neuropathic, microvascular, and macrovascular complications. In addition to the socioeconomic impact that diabetes and its complications has on patients, incremental financial costs are added to health-care systems. This study aimed to assess prevalence, patient-related factors, and referral patterns for patients with diabetes-related complications managed at Inkosi Albert Luthuli Central Hospital (IALCH) betweenJanuary 1, 2014 and December 31, 2015.

Methods: The retrospective cross-sectional study was done on all adult patients (aged $>18$ years) with diabetes consulted at IALCH. Primary outcome measures were the proportion with diabetes-related complications and the source of referrals. Logistic regression analysis was done to identify predictors of diabetes complications.

Results: Of all adult diabetes patients consulted, 7,761 (47.4\%) presented with one or more diabetes-related complications and 56\% $(4,321)$ had experienced macrovascular complications. Cardiovascular complications $(2,576,33 \%)$ were the most common complications, followed by peripheral vascular disease $(1,755,23 \%)$. Microvascular complications included retinopathy $(1,656,21 \%)$, nephropathy $(118,14 \%)$, and neuropathy $(702,9 \%)$. After multivariate analysis, all four factors (age $>58$ years, male sex, Indian ancestry, and non-insulin dependent diabetes mellitus remained statistically significant for an increased likelihood of developing cardiovascular complications. Indian ancestry was not associated with increased odds of peripheral vascular disease.

Conclusion: Macrovascular diseases were the main complications. Older age, male sex, Indian ancestry, and non-insulin dependent diabetes mellitus were associated with macrovascular complications. A combination of health-promotion and behaviour-modification programs is required prior to or early in the disease course. Appropriate and more aggressive management at primary-care level using evidence-based clinical guidelines is essential to prevent complications.

Keywords: patient referrals, diabetes-related complications, peripheral vascular disease, amputations

\section{Introduction}

Diabetes at one time was thought to be rare or undocumented in rural Africa, but over the past few decades it has emerged as an important incommunicable disease in sub-Saharan Africa. The International Diabetes Federation in 2017 estimated that the diabetic population in Africa would increase from 16 million to 45 million by 2045 - 2.56-fold. In South Africa, 1.826 million people - 5.4\% of the population — were living with diabetes in $2017 .{ }^{1}$ Diabetes mellitus, which ranked third in 
2014 in terms of cause of death, accounting for 5.1\%, moved to being the second-most common natural cause of death in 2016 , responsible for $5.5 \%$ of deaths. ${ }^{2}$ The high prevalence of diabetes is driven by rapid urbanization and globalization, unhealthy diets, increasingly sedentary lifestyles, and population aging. ${ }^{3}$ An estimated $77 \%$ of deaths due to diabetes in Africa occur in individuals $<60$ years of age. $^{4}$

Poor diabetes control can result in short- and long-term neuropathic, microvascular, and macrovascular complications, such as nephropathy, cardiovascular disease, neuropathy, and eye damage (diabetic retinopathy and cataracts). In South Africa, $32 \%$ of diabetes cases have eye complications, with $45 \%$ presenting with cataracts, $30.3 \%$ with some form of neuropathy, and $6.4 \%$ with chronic renal disease. $^{3}$

The public health-care system in South Africa is organized in a hierarchical manner (Figure 1). A majority of patients with diabetes are managed in primary health care, which is the first formal point of contact with the health services, normally delivered by a trained primary health-care nurse. District hospitals support primary health care and act as a gateway to more specialist care. Referrals to higher levels of care from district hospitals in most cases follow a hierarchical pathway to regional hospitals and then onward to provincial tertiary hospitals, and if required, to central hospitals.

Patients bypassing the referral system negatively impact the efficient utilization and planning of health and hospital services and their evaluation and management. In addition to the socioeconomic impact that diabetes and its complications has on patients, incremental financial costs are added to the health-care system.

\section{Objective}

The aim of this study was to measure prevalence, patientrelated factors, and referral patterns for patients with diabetes-related complications managed at Inkosi Albert Luthuli Central Hospital (IALCH).

\section{Methods}

\section{Study Design and Population}

This retrospective cross-sectional study was conducted on all adult patients (aged $>18$ years) with diabetes mellitus consulted (inpatient and outpatient) at IALCH between January 1, 2014 and December 31, 2015. Data for the 2015-2016 period is presented because though the study commenced in 2017, due to logistic challenges data collection was delayed.

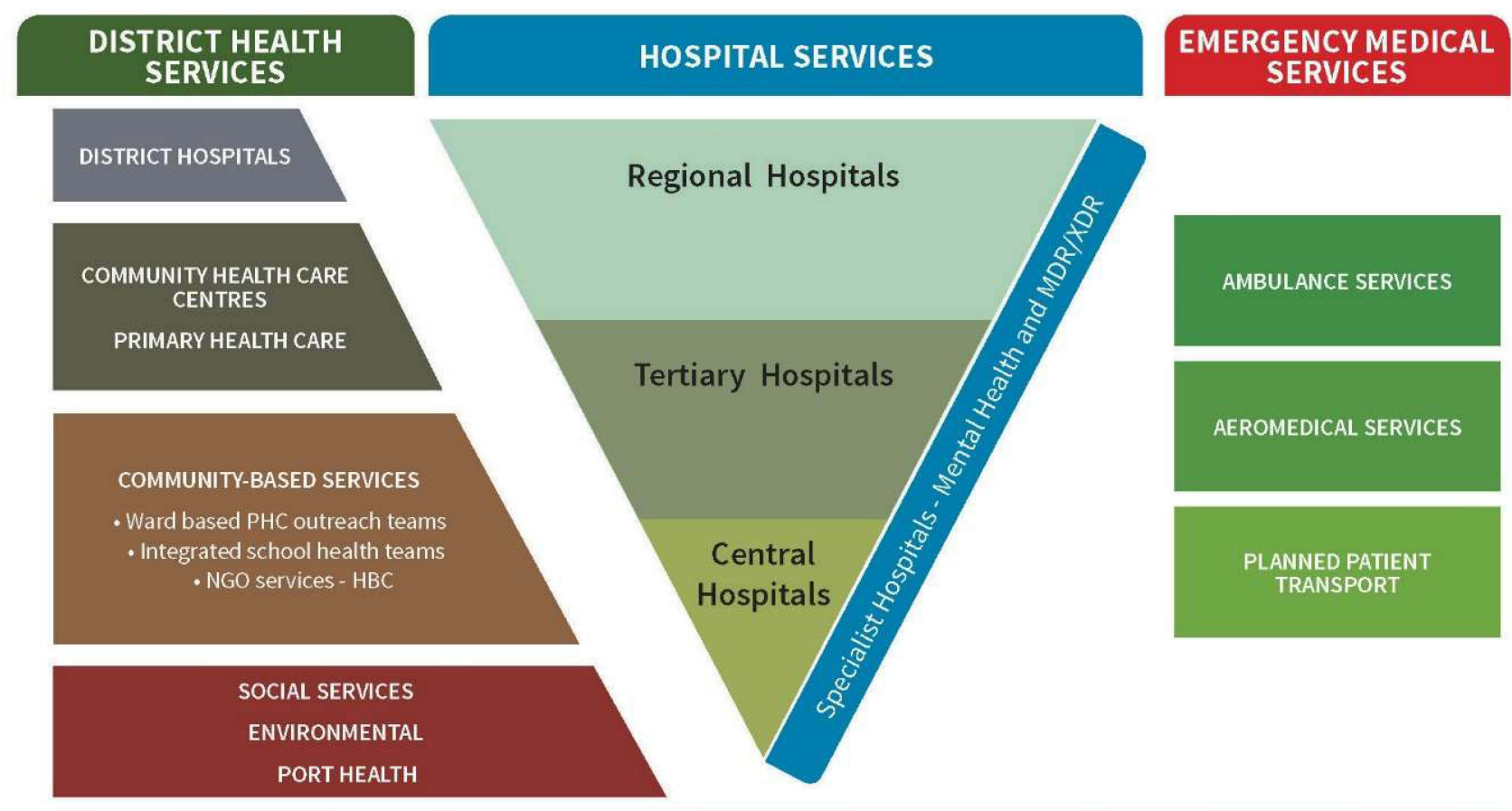

INTEGRATED REFERRAL SERVICES

Figure I Public health-care system in South Africa (source: National Department of Health). 


\section{Data Collection}

IALCH has an electronic health-record system that allows data storage and retrieval. Data were extracted from medical records for patients consulted with type 1 and type 2 diabetes. For the purposes of this study, we extracted specific information on patients with diabetes-related complications, sociodemographic factors, nature of complications, and source of referrals.

\section{Outcome Measures}

The primary outcome measures were proportion of patients with diabetes-related complications treated at IALCH and the source of referrals.

\section{Data Analysis}

Data were retrieved and extracted to a Microsoft Excel database. Descriptive statistics in the form of frequencies and proportions for categorical data and measures of central tendency were used for continuous data. Pearson $\# \chi^{2}$ test was used to determine associations between demographic factors and complications. Multivariate logistic regression was used to test for associations between dependent and independent variables for those with $p<0.1$ after bivariate analysis.

\section{Ethics}

There was no direct patient contact. Secondary data were extracted from the hospital information system, anonymized, and not linked. Therefore, the requirement for informed consent was waived. The study was approved by the Biomedical Research Ethics Committee of the University of KwaZulu-Natal, Durban (protocol BREC REF: BE221/ 17). Gatekeeper permission was received from IALCH and the Provincial Health Research and Knowledge Management Unit. All procedures were performed as per the ethical guidelines laid down by the Declaration of Helsinki (2013). There was no direct patient contact.

\section{Results}

\section{Prevalence of Complications}

During the period under review (January 2014 to December 2015), there were 13,495 adult patients with diabetes attending IALCH, representing 3.5\% of all outpatient consultations $(400,495)$. Of all adult diabetes patients consulted at IALCH, 7,761 patients (47.4\%) presented with one or more diabetes-related complications, while $61 \%(4,740)$ with complications were admitted during the study period.

\section{Nature of Complications}

In sum, 4,321 (56\%) patients had experienced macrovascular complications. Cardiovascular complications, ie, ischemic heart disease, myocardial infarction, heart failure, malignant dysrhythmia, and cardiac shock, were the most common $(2,576,33 \%)$, followed by peripheral vascular disease $(1,755,23 \%)$. Microvascular complications included retinopathy $(1,656,21 \%)$, nephropathy $(118,14$. $\%$ ), and neuropathy (702, 9\%) (Figure 2).

\section{Demographic Profile}

The mean age of patients with diabetes-related complications was $59 \pm 11.32$ (median 60) years. A majority were of Indian ancestry $(2,658,66 \%), 52 \%(4,034)$ were women, and $63 \%$ $(4,914)$ were not insulin-dependent. Of those with complications, $61 \%(4,740)$ had been admitted for further management (Table 1). There were significant relationships between age ( $>50$ years), Indian ancestry, non-insulin dependent diabetes, and diabetes-related complications.

\section{Associations Between Demographic Characteristics and Complications \\ Cardiovascular Complications}

Bivariate analysis indicated that patients $>58$ years of age (OR 1.08, 95\% CI 1.01-1.17), male (OR 2.05, 95\% CI 1.91-2.2), of Indian ancestry (OR 3.63, 95\% CI 3.353.94), and with non-insulin dependent diabetes (OR $1.84,95 \%$ CI 1.71-1.98) were significantly more likely to develop cardiovascular complications. After multivariate analysis, all four of these factors remained statistically significant for an increased likelihood of developing cardiovascular complications (Table 2).

\section{Peripheral Vascular Disease}

Bivariate and multivariate analyses indicated that age $>58$ years and male sex were associated with peripheral vascular disease, while patients with non-insulin dependent diabetes were less likely to develop peripheral vascular disease. Indian ancestry was not associated with increased odds of peripheral vascular disease (Table 2).

\section{Retinopathy}

Patient age $>58$ years of age, men, and of Indian ancestry were significantly less likely to develop retinopathy as a complication of diabetes. Type of diabetes was not significantly associated with likelihood of retinopathy (Table 2). 


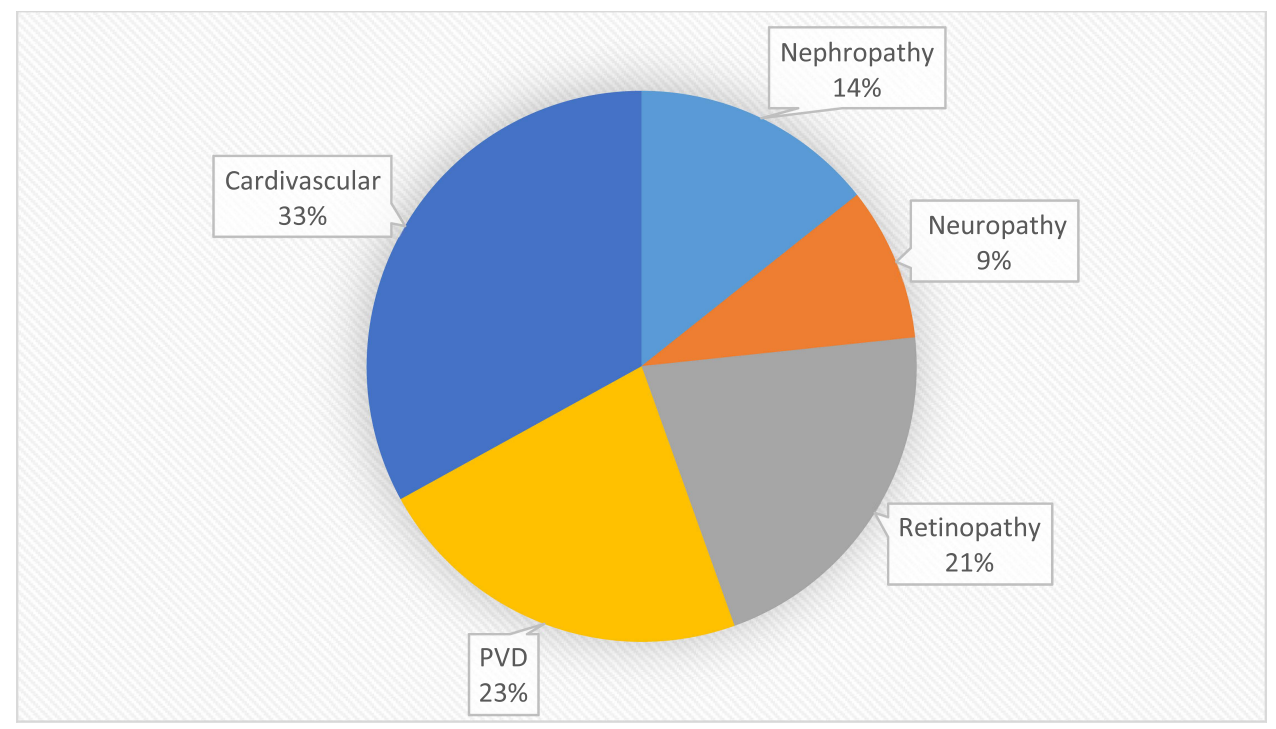

Figure 2 Nature of complications of patients admitted to IALCH between January 2014 and December 2015.

\section{Nephropathy}

Male sex was significantly associated with increased odds of diabetes-related nephropathy, while diabetes patients $>58$ years of age were significantly less likely to have diabetes-related nephropathy. Indian ancestry and type of diabetes were not associated with increased odds of diabetes-related nephropathy (Table 2).

\section{Neuropathy}

Diabetes patients that were of their Indian ancestry had significantly increased odds of having diabetes-related

Table I Demographic and Epidemiological Profile of Patients with Diabetes-Related Complications

\begin{tabular}{|c|c|c|c|c|c|c|c|c|c|c|c|c|}
\hline \multirow[b]{2}{*}{ Age (years) } & \multicolumn{2}{|c|}{ Cardiovascular } & \multicolumn{2}{|c|}{$\begin{array}{l}\text { Peripheral } \\
\text { Vascular }\end{array}$} & \multicolumn{2}{|c|}{ Retinopathy } & \multicolumn{2}{|c|}{ Nephropathy } & \multicolumn{2}{|c|}{ Neuropathy } & \multicolumn{2}{|c|}{$\begin{array}{c}\text { All } \\
\text { Complications }\end{array}$} \\
\hline & $\mathbf{n}$ & & $\mathbf{n}$ & & $\mathbf{n}$ & & $\mathbf{n}$ & & $\mathbf{n}$ & & $\mathbf{n}$ & \\
\hline $18-24$ & 100 & $2 \%$ & 47 & $3 \%$ & 65 & $4 \%$ & 56 & $5 \%$ & 36 & $5 \%$ & 226 & $3 \%$ \\
\hline $25-49$ & 721 & $15 \%$ & 315 & $18 \%$ & 258 & $16 \%$ & 167 & $15 \%$ & 110 & $16 \%$ & 1,223 & $16 \%$ \\
\hline$>50$ & 3,957 & $83 \%$ & I,389 & $79 \%$ & 1,317 & $80 \%$ & 885 & $80 \%$ & 554 & $79 \%$ & $6,312^{\text {** }}$ & $81 \%$ \\
\hline \multicolumn{13}{|l|}{ Sex } \\
\hline Female & 2,290 & $48 \%$ & 811 & $46 \%$ & 1,036 & $63 \%$ & 612 & $55 \%$ & 419 & $60 \%$ & 4,034 & $52 \%$ \\
\hline Male & 2,488 & $52 \%$ & 940 & $54 \%$ & 604 & $37 \%$ & 496 & $45 \%$ & 281 & $40 \%$ & 3,727 & $48 \%$ \\
\hline \multicolumn{13}{|l|}{ Ethnicity } \\
\hline Indian & $\mathrm{I}, 475$ & $65 \%$ & 668 & $67 \%$ & 634 & $67 \%$ & 400 & $65 \%$ & 253 & $66 \%$ & $4,506 *$ & $59 \%$ \\
\hline African & 541 & $24 \%$ & 216 & $22 \%$ & 220 & $23 \%$ & $|4|$ & $23 \%$ & 91 & $24 \%$ & 2425 & $32 \%$ \\
\hline Mixed & 77 & $3 \%$ & 30 & $3 \%$ & 24 & $3 \%$ & 18 & $3 \%$ & 12 & $3 \%$ & 244 & $3 \%$ \\
\hline Caucasian & 122 & $6 \%$ & 51 & $5 \%$ & 48 & $5 \%$ & 36 & $6 \%$ & 20 & $5 \%$ & 380 & $5 \%$ \\
\hline Other & 61 & $3 \%$ & 25 & $3 \%$ & 21 & $2 \%$ & 17 & $3 \%$ & 8 & $2 \%$ & & \\
\hline \multicolumn{13}{|l|}{ Diabetes type } \\
\hline Insulin-dependent & $\mathrm{I}, 457$ & $31 \%$ & 845 & $48 \%$ & 683 & $42 \%$ & 425 & $39 \%$ & 257 & $37 \%$ & 2,847 & $37 \%$ \\
\hline Non-insulin dependent & 3,321 & $69 \%$ & 906 & $52 \%$ & 957 & $58 \%$ & 683 & $61 \%$ & 443 & $63 \%$ & $4,914 *$ & $63 \%$ \\
\hline \multicolumn{13}{|l|}{ Hospital status } \\
\hline Admitted & 2,007 & $42 \%$ & 647 & $63 \%$ & 667 & $41 \%$ & 330 & $30 \%$ & 218 & $69 \%$ & 4,740 & $61 \%$ \\
\hline Never admitted & 2,771 & $58 \%$ & $\mathrm{I}, 104$ & $37 \%$ & 973 & $59 \%$ & 778 & $70 \%$ & 482 & $31 \%$ & 3,021 & $39 \%$ \\
\hline
\end{tabular}

Notes: $*_{p}<0.05 ; * *_{p}<0.001$. 
neuropathy, while diabetes patients $>58$ years of age were significantly less likely to have diabetes-related neuropathy. Sex and type of diabetes were not associated with increased odds of diabetes-related neuropathy (Table 2).

\section{Referral Patterns}

Sixteen $(0.25 \%)$ patients had been referred from another central hospital (Nelson Mandela Academic Hospital) in
Eastern Cape Province. A total of 829 patients (12.95\%) had been referred from tertiary hospitals. These hospitals offer basic specialist services, but not subspecialties. A majority of referrals $(3,204,50.05 \%)$ came from regional hospitals. These facilities provide limited specialist services. There were also referrals $(364,5.74 \%)$ from district hospitals. In sum, 774 (12.09\%) referrals were from specialized facilities that offer services ranging

Table 2 Associations Between Demographic Variables and Diabetes-Related Complications

\begin{tabular}{|c|c|c|c|c|c|c|}
\hline & \multicolumn{6}{|c|}{ Cardiovascular Disease } \\
\hline & Unadjusted OR & $95 \% \mathrm{Cl}$ & $p$ & Adjusted OR & $95 \% \mathrm{Cl}$ & $p$ \\
\hline Age $>58$ years versus $<58$ years & 1.08 & $1.01-1.17$ & 0.02 & 1.17 & $1.08-1.26$ & $<0.001$ \\
\hline Male versus female sex & 2.05 & $1.91-2.2$ & $<0.001$ & 2.01 & $1.87-2.17$ & $<0.001$ \\
\hline Indian ancestry versus other ethnicities & 3.63 & $3.35-3.94$ & $<0.001$ & 3.52 & $3.25-3.83$ & $<0.001$ \\
\hline \multirow{3}{*}{$\begin{array}{l}\text { Non-insulin dependent diabetes versus diabetes } \\
\text { mellitus type I }\end{array}$} & 1.84 & $1.7 \mathrm{I}-1.98$ & $<0.001$ & 1.78 & $1.64-1.92$ & $<0.001$ \\
\hline & \multicolumn{6}{|c|}{ Peripheral vascular disease } \\
\hline & Unadjusted OR & $95 \% \mathrm{Cl}$ & $p$ & Adjusted OR & $95 \% \mathrm{Cl}$ & $\mathbf{p}$ \\
\hline Age $>58$ years versus $<58$ years & 1.83 & $1.64-2.04$ & $<0.001$ & 1.85 & $1.65-2.06$ & $<0.001$ \\
\hline Male versus female sex & 1.83 & $1.65-2.02$ & $<0.001$ & 1.9 & $1.7 \mid-2.10$ & $<0.001$ \\
\hline Indian ancestry versus other ethnicities & 1.09 & $0.98-1.21$ & 0.11 & 1.09 & $0.98-1.21$ & 0.1 \\
\hline \multirow{3}{*}{$\begin{array}{l}\text { Non-insulin dependent diabetes versus diabetes } \\
\text { mellitus type I }\end{array}$} & 0.67 & $0.60-0.74$ & $<0.001$ & 0.65 & $0.58-0.72$ & $<0.001$ \\
\hline & \multicolumn{6}{|c|}{ Retinopathy } \\
\hline & Unadjusted OR & $95 \% \mathrm{Cl}$ & $p$ & Adjusted OR & $95 \% \mathrm{Cl}$ & $\mathbf{p}$ \\
\hline Age $>58$ versus Age $<58$ years & 0.66 & $0.59-0.73$ & $<0.001$ & 0.65 & $0.59-0.73$ & $<0.001$ \\
\hline Male versus female sex & 0.83 & $0.74-0.92$ & $<0.001$ & 0.83 & $0.75-0.92$ & $<0.001$ \\
\hline Indian ancestry versus other ethnicities & 0.81 & $0.73-0.90$ & $<0.001$ & 0.82 & $0.74-0.91$ & $<0.001$ \\
\hline \multirow{3}{*}{$\begin{array}{l}\text { Non-insulin dependent diabetes versus diabetes } \\
\text { mellitus type I }\end{array}$} & 0.91 & $0.82-1.02$ & 0.07 & 0.92 & $0.83-1.02$ & 0.122 \\
\hline & \multicolumn{6}{|c|}{ Nephropathy } \\
\hline & Unadjusted OR & $95 \% \mathrm{Cl}$ & $\mathbf{p}$ & Adjusted OR & $95 \% \mathrm{Cl}$ & $p$ \\
\hline Age $>58$ years versus $<58$ years & 0.72 & $0.63-0.81$ & $<0.001$ & 0.72 & $0.63-0.80$ & $<0.001$ \\
\hline Male versus female sex & 1.19 & $1.05-1.35$ & $<0.001$ & 1.18 & $1.04-1.34$ & 0.01 \\
\hline Indian ancestry versus other ethnicities & 1.04 & $0.92-1.18$ & 0.53 & 1.02 & $0.90-1.16$ & 0.29 \\
\hline \multirow{3}{*}{$\begin{array}{l}\text { Non-insulin dependent diabetes versus diabetes } \\
\text { mellitus type I }\end{array}$} & 1.07 & $0.93-1.21$ & 0.36 & 1.05 & $0.92-1.19$ & 0.71 \\
\hline & \multicolumn{6}{|c|}{ Neuropathy } \\
\hline & Unadjusted OR & $95 \% \mathrm{Cl}$ & $p$ & Adjusted OR & $95 \% \mathrm{Cl}$ & $\mathbf{p}$ \\
\hline Age $>58$ years versus $<58$ years & 0.78 & $0.67-0.91$ & $<0.001$ & 0.78 & $0.67-0.92$ & 0.002 \\
\hline Male versus female sex & 0.97 & $0.83-1.14$ & 0.72 & 0.95 & $0.8 I-1.1 I$ & 0.48 \\
\hline Indian ancestry versus other ethnicities & 1.3 & $1.10-1.53$ & $<0.001$ & 1.29 & $|.09-| .5 \mid$ & 0.002 \\
\hline $\begin{array}{l}\text { Non-insulin dependent diabetes versus diabetes } \\
\text { mellitus type I }\end{array}$ & 1.14 & $0.97-1.34$ & 0.1 & 1.13 & $0.96-1.32$ & 0.14 \\
\hline
\end{tabular}


Table 3 Frequency Distribution of Points of Referral for Diabetes-Related Complications

\begin{tabular}{|l|r|r|}
\hline Facility type & $\mathbf{n}$ & $\%$ \\
\hline Central hospital (external — Eastern Cape) & 16 & 0.25 \\
Tertiary hospital & 829 & 12.95 \\
Regional hospital & 3,204 & 50.05 \\
District hospital & 364 & 5.74 \\
Specialized hospital & 774 & 12.09 \\
Community/primary health care & 159 & 2.32 \\
Unclassified & 1,056 & 16.49 \\
Total & 6,402 & 100 \\
\hline
\end{tabular}

from psychiatry, mother and child health, rehabilitation, ophthalmology, and various others, while 159 (2.32\%) were referred from other facilities, prisons, the military, private hospitals, general practitioners, primary health-care facilities, and others directly from home. Points of referral for 1,056 patients $(16.49 \%)$ were unclassified (Table 3).

\section{Discussion}

Diabetes-related complications impose a great burden on tertiary and quaternary care in South Africa. In this study, 7,761 patients (47.4\%) consulted during the 2-year period presented with one or more diabetes-related complications. Our findings are similar to reports from Ethiopia (48.3\%), ${ }^{6}$ New Zealand $(43.5 \%)^{7}$ and Kuwait $(40.6 \%),{ }^{8}$ though findings from Australia (32.8\%) $)^{9}$ showed much lower prevalence. However, in contrast to the findings in the current study, results from the 2011 Survey on Living with Chronic Diseases in Canada on the weighted prevalence of 16 diabetes-related complications showed that among patients with self-reported diabetes, $80.26 \%$ reported having at least one type of diabetes-related complication. ${ }^{10}$

Overall, $61 \%$ of patients with diabetes-related complications had been admitted at least once during the study period, representing $35 \%$ of all diabetes patients consulted at the hospital. This high proportion of diabetes complication-related admissions at IALCH was most likely due to the quaternary status of the hospital, where patients from across the province are referred for specialist and subspecialist services.

The nature of complications in the current study follows global trends. Cardiovascular complications $(2,576$, $33 \%)$ - ischemic heart disease, myocardial infarction, heart failure, malignant dysrhythmia, and cardiac shock - were the most common complications, followed by peripheral vascular disease $(1,755,23 \%)$. These findings are consistent with results from Kuwait, where acute coronary syndrome $(27.2 \%)$, heart failure $(11.2 \%)$, cerebrovascular accidents (10.3\%), and chronic obstructive airway disease $(3.6 \%)$ were the most common reasons for admission. ${ }^{8}$ In the US state of Georgia, the three most common discharges have been identified as for those of the circulatory system (33\%), endocrine, nutritional, metabolic, and immunity disorders (13\%), and diseases of the respiratory system: (11\%) among patients with a diagnosis of diabetes. ${ }^{11}$ Congestive heart failure, coronary atherosclerosis, and acute myocardial infarction were the top-, second-, and fifth-most frequently found unique diagnoses, respectively, among patients with diabetes. ${ }^{11}$ In a retrospective record-based study conducted at Goa Medical College from August 2009 to May 2012 in a tertiary hospital in India, $31.4 \%$ of patients had macrovascular complications and $34.4 \%$ at least one microvascular complication. Coronary artery disease was the most common complication. ${ }^{12}$

Overall, $59 \%$ of patients with diabetes-related complications in the current study were of Indian ancestry. The South African Indian population has the highest prevalence of diabetes nationally, and in KwaZulu Natal specifically. A recent study reported diabetes prevalence (age-standardi zed) to be about $20 \%$ amongs Indians living in a suburb near Durban. ${ }^{13}$ Typically, South Asians have a lower bodymass index, more visceral fat, early diabetes onset, and significant historical changes, such as migration, lifestyle, and environmental factors, contributing to a high prevalence of diabetes ${ }^{14}$ and related complications.

Older age, male sex, and long-term chronic diabetes were associated with macrovascular complications. However, younger diabetes patients, women, and those with type 1 diabetes were more likely to develop microvascular complications. The Irish Longitudinal Study on Ageing indicated the risk of macrovascular complications was higher among older participants (RR 1.6 [95\% CI 1.1-2.5] in those aged 65-74 years and RR 2.0 [95\% CI 1.2-3.2] in those aged $\geq 75$ years versus 50 64 years). ${ }^{15}$ Similarly, results from a 10 -year cohort study in a large integrated health-care system in the US indicated that those with cardiovascular (coronary artery disease, congestive heart failure, and cerebrovascular disease) followed by diabetic eye disease had the highest incidence of nonfatal complications. Congestive heart failure and cerebrovascular disease increased most dramatically with advancing age. ${ }^{16}$ Similarly, in India there was a significant association found for rising prevalence of all 
complications with age $(p<0.05)$. Duration of diabetes also showed a significantly positive trend for all complications $(p<0.05) .{ }^{12}$

Vascular endothelial damage is the main pathological mechanism responsible for inducing macrovascular complications. A combination of factors, such as hyperglycemia, insulin resistance, dyslipidemia, hypertension, and chronic inflammation, in combination with diabetes as an independent risk factor, predisposes an individual to endothelial damage. ${ }^{17}$ In addition to diabetes, other modifiable risk factors, such as hypertension, smoking, obesity (ie, waist:hip ratio), dyslipidemia, ahistory of cardiovascular disease, and physical inactivity, increase the risk of peripheral vascular disease. ${ }^{18}$

A well-functioning referral system that allows for continuity across different tiers of care is central to the delivery of efficient and effective health care. Though the referral pattern in this studyappeared to be in conformance with the hierarchical nature of the health-care system, the nature of complications based on underlying pathophysiological mechanisms and associated risk factors highlight important underlying weaknesses in the delivery of health care for patients with diabetes. In the last decade, South Africa adopted a very cure-focused health service, with recipients of care then taking responsibility for their own health. ${ }^{19}$ As a result, patients demonstrated inadequate knowledge of diabetes and its complications, poor glycemic control, and poor knowledge of treatment targets. ${ }^{20}$ Furthermore, rural or periurban populations of low socioeconomic status and with limited education have challenges with self-monitoring, self-management, and compliance with treatment of diabetes. ${ }^{21}$

Over the last two decades, there has been a shift from a hospital-centric approach toward a primary health-care approach. ${ }^{5}$ The primary-care approach has seen a shift from disease treatment to a focus on wellness, healthy living, disease prevention, and rehabilitation. These changes are facilitated by a combination of the shift in disease burden toward chronic diseases requiring longterm management from a biopsychosocial perspective, increasing life expectancy, and more informed patients. Furthermore, budgetary constraints require hospitals to move away from the traditional model of offering all services under one roof toward one that offers clearly defined services.

In addition to patient factors, primary health-care clinicians fail to initiate or intensify treatment of patients with diabetes whose health may improve as a result of early or timely follow-up. ${ }^{22}$ Clinicians at the primary healthcare level have a tendency to continue with current treatment despite blood results $\left(\mathrm{HbA}_{1 \mathrm{c}} \geq 7 \%\right)$ suggesting that treatment be modified. ${ }^{23}$ There has been limited focus on nonpharmaceutical interventions that should be promoted at the primary health-care level. Physical activity and a healthy diet are fundamental in the prevention of diabetes, and their promotion should form central components in prevention initiatives. ${ }^{24}$

\section{Limitations}

The strengths of this study were that it included all diabetes patients admitted to this large referral hospital during a 2-year period and that there was no need for any sampling framework. Our study was based on data extracted from an electronic information system at a quaternary hospital. However, we did not assess comorbidities, severity of complications, or appropriateness of referrals.

Study limitations included the retrospective nature of the study, relying on electronicmedical record coding for diagnoses (which may miss some data, especially peripheral vascular disease, or include incorrect diagnoses). As the hospital is a major specialist/tertiary hospital, patients seen there will not necessarily represent Durban/South African data as a whole.

\section{Conclusion}

Macrovascular conditions in the form of cardiovascular and peripheral vascular diseases were the main category of complications. For patients with diabetes consulted at IALCH, older age, male sex, Indian ancestry, and noninsulin dependent diabetes were associated with macrovascular complications. These risk factors point to duration of underlying disease, adequate management, and external behavioral factors that influence the clinical outcome of the disease. To mitigate or reduce the risk of complications and referral to the apex of the health-care system, a combination of primordial and primary preventions through a combination of health-promotion and behavior-modification programms is required prior to or early in the disease process. After disease onset, appropriate and more aggressive management at the primary health-care level using evidence-based clinical guidelines is essential to prevent complications. Simultaneously, there is a need to educate health professionals on updated guidelines and strengthen implementation of the integrated clinical services model ${ }^{25}$ to treat the patient, rather than the disease. It 
is also vital to inform health professionals on how to empower their patients with nonpharmaceutical strategies.

\section{Disclosure}

The authors report no conflicts of interest in this work.

\section{References}

1. da Rocha Fernandes J, Ogurtsova K, Linnenkamp U, et al. IDF diabetes atlas estimates of 2014 global health expenditures on diabetes. Diabetes Res Clin Pract. 2016;117:48-54. doi:10.1016/j. diabres.2016.04.016

2. Statistics South Africa. Mortality and Causes of Death in South Africa, 2015: Findings from Death Notification. Pretoria: Statistics South Africa; 2017.

3. Peer N, Kengne AP, Motala AA, et al. Diabetes in the Africa Region: an update. Diabetes Res Clin Pract. 2014;103:197-205. doi:10.1016/ j.diabres.2013.11.006

4. Cho NH, Shaw JE, Karuranga S, et al. IDF diabetes atlas: global estimates of diabetes prevalence for 2017 and projections for 2045 . Diabetes Res Clin Pract. 2018;138:271-281. doi:10.1016/j.diabres. 2018.02.023

5. National Department of Health. White Paper on the Transformation of the Health System. Pretoria: Government Gazette; 1997.

6. Kefale AT, Eshetie TC, Gudina EK. Hospitalization pattern and treatment outcome among diabetic patients admitted to a teaching hospital in Ethiopia: a Prospective Observational Study. $J$ Health Med Nurs. 2016;28:34-41.

7. Tomlin AM, Tilyard MW, Dovey SM, et al. Hospital admissions in diabetic and non-diabetic patients: a case-control study. Diabetes Res Clin Pract. 2006;73:260-267. doi:10.1016/j.diabres.2006.01.008

8. Al-Adsani AMS, Abdulla KA. Reasons for hospitalizations in adults with diabetes in Kuwait. Int $J$ Diabetes Mellit. 2015;3:65-69. doi:10.1016/j.ijdm.2011.01.008

9. Comino EJ, Harris MF, Islam MD, et al. Impact of diabetes on hospital admission and length of stay among a general population aged 45 year or more: a record linkage study. BMC Health Serv Res. 2015;15:12. doi:10.1186/s12913-014-0666-2

10. Yaghoubi M, Mansell K, Vatanparast H, et al. Prevalence of type 1 and type 2 diabetes-related complications and their association with determinants identified in Canada's survey on living with chronic diseases-diabetes component. Can J Diabetes. 2020;44:304-311. e303. doi:10.1016/j.jcjd.2019.09.001

11. Cook CB, Tsui C, Ziemer DC, et al. Common reasons for hospitalization in urban diabetes patients. Ethn Dis. 2006;16:391-397.

12. Ankush AD, Gomes E, Dessai A. Complications in advanced diabetics in a tertiary care centre: a Retrospective Registry-Based Study. J Clin Diagn Res. 2016;10:Oc15-19. doi:10.7860/jcdr/2016/152 68.7583
13. Prakaschandra DR, Esterhuizen TM, Motala AA, et al. High prevalence of cardiovascular risk factors in Durban South African Indians: the Phoenix Lifestyle Project. S Afr Med J. 2016;106:284-289. doi:10.7196/SAMJ.2016.v106i3.9837

14. Gujral UP, Pradeepa R, Weber MB, et al. Type 2 diabetes in South Asians: similarities and differences with white Caucasian and other populations. Ann N Y Acad Sci. 2013;1281:51-63. doi:10.1111/ j.1749-6632.2012.06838.x

15. Tracey ML, McHugh SM, Fitzgerald AP, et al. Risk factors for macro- and microvascular complications among older adults with diagnosed type 2 diabetes: findings from The Irish Longitudinal Study on Ageing. J Diabetes Res. 2016;2016:5975903. doi:10.1155/ 2016/5975903

16. Huang ES, Laiteerapong N, Liu JY, et al. Rates of complications and mortality in older patients with diabetes mellitus: the diabetes and aging study. JAMA Intern Med. 2014;174:251-258. doi:10.1001/ jamainternmed.2013.12956

17. Beckman JA, Creager MA, Libby P. Diabetes and atherosclerosis: epidemiology, pathophysiology, and management. JAMA. 2002;28 7:2570-2581. doi:10.1001/jama.287.19.2570

18. Wattanakit K, Folsom AR, Selvin E, et al. Risk factors for peripheral arterial disease incidence in persons with diabetes: the Atherosclerosis Risk in Communities (ARIC) Study. Atherosclerosis. 2005;180:389-397. doi:10.1016/j.atherosclerosis.2004.11.024

19. Mahomed OH, Asmall S, Freeman M. An integrated chronic disease management model: a diagonal approach to health system strengthening in South Africa. $J$ Health Care Poor Underserved. 2014;25:1723-1729. doi:10.1353/hpu.2014.0176

20. Adeniyi OV, Yogeswaran P, Wright G, et al. Diabetic patients' perspectives on the challenges of glycaemic control. Afr J Prim Health Care Fam Med. 2015;7. doi:10.4102/phcfm.v7i1.767

21. Govender RD, Gathiram P, Panajatovic M. Poor control and management of type 2 diabetes mellitus at an under-resourced South African Hospital: is it a case of clinical inertia? $S$ Afr Fam Pract. 2017;59:154-159. doi:10.1080/20786190.2017.1307909

22. O'Connor PJ, Sperl-Hillen JAM, Johnson PE, et al. Clinical inertia and outpatient medical errors. In: Henriksen K, Battles JB, Marks ES, et al., editors. Advances in Patient Safety: From Research to Implementation (Volume 2: Concepts and Methodology). Rockville (MD); 2005.

23. Larme AC, Pugh JA. Evidence-based guidelines meet the real world: the case of diabetes care. Diabetes Care. 2001;24:1728-1733. doi:10. 2337/diacare.24.10.1728

24. Schwarz PE, Greaves CJ, Lindström J, Yates T, Davies MJ. Nonpharmacological interventions for the prevention of type 2 diabetes mellitus. Nat Rev Endocrinol. 2012;8:363-373. doi:10.1038/ nrendo.2011.232

25. Mahomed O, Asmall S. Integrated Clinical Services Management. Pretoria: National Department of Health; 2017.

Diabetes, Metabolic Syndrome and Obesity: Targets and Therapy

\section{Dovepress}

\section{Publish your work in this journal}

Diabetes, Metabolic Syndrome and Obesity: Targets and Therapy is an international, peer-reviewed open-access journal committed to the rapid publication of the latest laboratory and clinical findings in the fields of diabetes, metabolic syndrome and obesity research. Original research, review, case reports, hypothesis formation, expert opinion and commentaries are all considered for publication. The manuscript management system is completely online and includes a very quick and fair peer-review system, which is all easy to use. Visit http://www.dovepress.com/testimonials.php to read real quotes from published authors. 